\title{
Multimedia and Textual Reading Comprehension: Multimedia as Personal Learning Environment's Enriching Format
}

\author{
J. Daniel García ${ }^{1 *} \mathbb{B}$, Eduardo Rigo² (10), Rafael Jiménez ${ }^{3}$ \\ ${ }^{1}$ Center for Modern Languages, School of Humanities and Social Sciences, Nanyang Technological Univer- \\ sity, Singapore \{JoseDaniel@ntu.edu.sg\} \\ ${ }^{2}$ Psychology Faculty, Baleares Islands University, Spain \{e.rigo@uib.es\} \\ ${ }^{3}$ Psychology Faculty, Baleares Islands University, Spain \{rafa.jimenez@uib.es\} \\ Received on 2 April 2016; revised on 6 May 2016; accepted on 21 June 2016; published on 15 January 2017 \\ DOI: 10.7821/naer.2017.1.180 \\ (ए) WENG-ND
}

\begin{abstract}
In this article we will discuss part of a piece of research that was conducted with two 4ESO groups. Textual learning is opposed to multimedia learning within the context of PLE's (Personal Learning Environment) reading tools and strategies. In the research an analysis was made of whether it would be possible to improve the reading process through multimedia over a school term in two different aspects; one evolutionary with six classroom exercises and one evaluation with a final exercise. Concretely, this article states the number of question mistakes that the students made. The data indicates that there is a better evolution in students that performed the multimedia dynamic, although there are not any relevant differences in the final evaluation.
\end{abstract}

$\begin{array}{lllr}\text { KEYWORDS: } & \text { HIGH SCHOOL EDUCATION, LITERACY, } \\ \text { COGNITIVE } & \text { PROCESSES, } & \text { ALTERNATIVE } & \text { MODES }\end{array}$ EDUCATION

\section{INTRODUCTION}

The irruption of digital tools in education has made Social Sciences take a particular interest in their study. Within this field, there is a crucial element: the democratisation of video. While in the past it was necessary to have more complex technical media (such as projectors, digital carts), today it is quite simple for a teacher to have the appropriate tools to show a video in a classroom. To this we can add the estrangement of teenagers from written media and their major exposure to multimedia. In line with this idea, it should be mentioned that there is a strong movement towards autonomous multimedia learning for teenagers, who are increasingly including it in their daily practices. A significant part of this movement takes place through a video platform called YouTube. It was conceived as a simple no-place where teenagers could share their videos, to become a real element of change, able to convene, report and provoke movements at a high political level; what Moises Naimm calls The YouTube Effect (Naimm, 2007 The flexibility and diversification of this platform have been studied, for example in high education (C. Orus et al., 2016) proving to be a very useful tool to create a more active and autonomous form of

*To whom correspondence should be addressed:

Universitat de les Illes Balears, Campus Universitario

Carretera de Valldemossa km. 7,2

07122 Palma de Mallorca. Islas Baleares. España learning from the students. In this learning context, completely linked to the idea of collaborative and autonomous learning of the PLE, is where this article is based. Subsequently, we will try to determine exactly which instance of the PLE we are studying.

In 2007 Graham Attwell (Atwell, 2007) indicated that the PLE concept (then in its infancy) recognises a continuous and auto regulatory learning from the subject, in different contexts and situations. His reference was the discussions that took place in 2006, in the Association of Learning Technology's annual conference. Likewise, we can see that in 2008 the concept was still being discussed; so, van Haremelen (van Haremelen, 2008) was widening Atwell's idea of the PLE by adding concepts such as planning, objectives and, what's most important, that it was a process that could be performed autonomously or with the support of others.

In both definitions, a reference was made to generic aspects of the term; therefore we will use 2010's Jordi Adell's and Linda Castañeda's definition, which is more operational, and in which they tell us that the PLE is: "a set of tools, information sources, connections and activities that each person uses on a regular basis to learn" (Adell \& Castañeda, 2010, p. 23) We are especially interested in how they define the parts of the PLE into 3:

(1) Tools and strategies for reading (understood in the broadest sense): the sources of information as an object or device (media libraries).

(2) Tools and Strategies for reflection: environments or services in which information is transformed, mixed and re elaborated (sites where someone can write, comment, analyse, recreate, evaluate, recommend, publish, etc.).

(3) Relationship tools and strategies: environments where we can interact with people that we learn from and people that we learn with (Castañeda \& Adell, 2011, p. 89).

In this article, we are going to focus on the first part. In order to establish the base of a PLE it is crucial that the subject starts from a documental basis. This basis is traditionally a textual one. In our research we performed a text comprehension study by comparing text material versus multimedia material. Again, Adell and Castañeda give us a table to express the type of materials that may be part of the PLE's first part. (Castañeda \& Adell, 2013, p. 16): 
Table 1. Knowledge sources

\begin{tabular}{ll}
\hline & $\begin{array}{l}\text { Tools: newsletters, blogs, video } \\
\text { channels, RSS lists, etc. }\end{array}$ \\
\cline { 2 - 2 } To read/access to the information & $\begin{array}{l}\text { Mechanisms: searching, curiosity, } \\
\text { initiative, etc }\end{array}$ \\
\cline { 2 - 2 } & $\begin{array}{l}\text { Activities: lecture, reading, } \\
\text { headlines revision, multimedia } \\
\text { watching }\end{array}$ \\
\hline
\end{tabular}

Our research explores the possibility of performing two of the activities set forth in Table 1 as one: the textual reading and multimedia reading depending on a single general cognitive ability: human understanding. This idea is defended by Ann Morton Gernsbacher (1995) and she calls it: Structure Building Framework; according to this theory, human understanding is based on the formation of mental structures. In the process, we can find at least three components. First, Laying a Foundation (Gernsbacher, 1995, p. 289), is nothing more than the preparation, the foundation on which the structure will be held by the Agent of Comprehension or "comprehender", which uses the first information received to initiate this process. The second is the Mapping (Gernsbacher, 1995, p. 290); if the incoming information is coherent with what we have in the formed structure, it will accumulate in layers and increase or enhance it. Finally, the third process is Shifting (Gernsbacher, 1995, p. 291), whereby if the incoming information is not coherent with the structure, the latter will be displaced, and the construction of a new substructure will start. What seems more interesting about this process is that the adults of advanced level, with a good ability to understand written language, have a similar ability to understand spoken language. This is one of the reasons why Gernsbacher proclaims that many of the processes and mechanisms involved in language comprehension are general processes and mechanisms. Therefore, the reasons why adults differ in their comprehension skills are not specific to language in fact the individuals differ in their abilities to build coherent mental representations, regardless of mode. ${ }^{i}$
That is why it is best to call a marker to represent their skill in understanding. Said marker, (denominated Comprehension General Skill which was defined by Perfetti, Goldamn and Lesgold) refers to poor access to information recently assimilated by listening to or reading texts (Perfetti and Goldman, 1976; Perfetti and Lesgold, 1977). Gernsbacher, Varner and Faust extend the meaning to visual texts as well (Gernsbacher, Varner and Faust, 1990, p. 432). In general, the comprehension agents have very little disposition to remembering the information they have recently understood, and even more so if it is superficial. In summary, if an individual is less qualified to read or understand an oral text, they will also be to understand a visual presentation, provided that it concerns equivalent contents ${ }^{\text {ii }}$

Bellow, an outline of the theory of self-development can be seen (Figure 1).

Along with this idea of reading as a cognitive general ability, we explore another theory that serves as a theoretical framework: The multimedia learning (Mayer, 2005, 2008, 2011). Mostly belonging to Richard E. Mayer and based on a principle he called "Principle of Multimedia Learning" (Mayer, 2005, p. 1), it tells us that people can learn in a more profound way if the material is presented in multimedia format rather than in a simple format (written words, still images...) According to Richard E. Mayer (Mayer, 2005, 2008, 2011), in order to learn multimedia material, it is necessary to process it through two channels: sight and hearing, the processing capacity is limited (Sweller, 1988, p. 261) and active. There are three types of memory in the process: the sensory, the work memory, and finally, the long-term memory where the meaning is integrated. It is, in short, a process rich in cognitive implications. For Mayer, there are three principles on which he bases his theory. These are the "Principle of the two channels" (sight and hearing), the "principle of the limited capacity" that each learner can support each input, and finally, the "principle of active processing” (Mayer, 2011, p. 82).

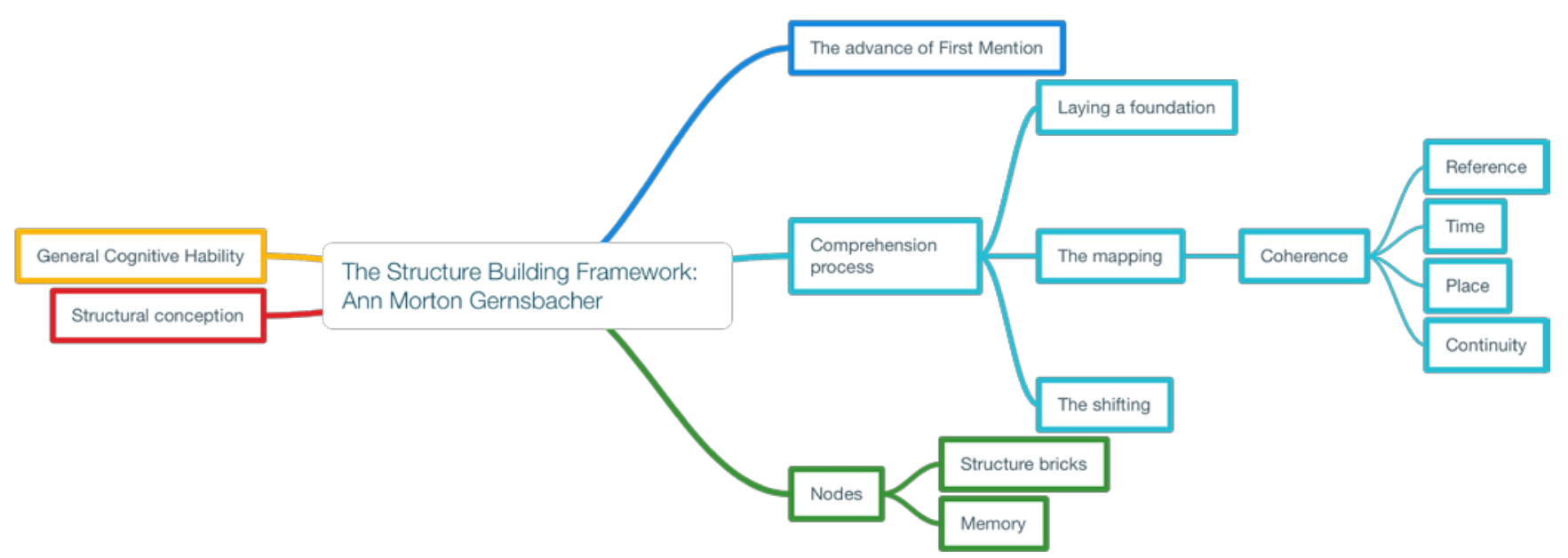

Figure 1. SBF graphic summary 
In order for the information received by the receiver to become knowledge, it is essential that it exercises some active functions: selecting relevant information, organizing it within relevant cognitive structures and of good quality, and finally, integration into prior knowledge to turn that information into integrated knowledge in the long-term memory. These functions correspond to the memories mentioned above. That is, the individual must be mentally aware of the process for optimum processing, which is metacognition. Although we will not develop this point, it is also associated with PLE in the reflexion aspect in the individual line, without making reference to the PLN.

Again, an outline of the self-development theory is attached (Figure 2).

\section{OBJECTIVES AND HYPOTHESIS}

Based on this theoretical framework, during the school year $2012 / 2013$, we conducted a study on two groups in 4th grade of Secondary Education (ESO-15 years old students) in Agora Portals International School, a private school located in Mallorca (Spain) with high social class families with high purchasing power. The research problems we decided to confront were the following: Is there a difference between working on the reading comprehension of fourth ESO students with texts rather than working on it with multimedia? What differences can we see in the process? Is its behaviour different compared to a multimedia test?

To try to answer these questions, a series of hypotheses and sub-hypotheses were established. Fundamentally, two aspects were studied: evolution and assessment. In this article, we explore two sub-hypotheses from the research.

Sub-hypothesis 1 (H1): "It is expected to observe significant differences in the evolution of the number of question mistakes that a multimedia and a textual learner makes during classroom exercises. Specifically, it is expected that the number of question mistakes in multimedia learners will decrease more sharply than in the case of textual learners". Going back to the introduction, if we remember what Gernsbacher tells us, reading comprehension is not a specific ability but a general ability, which covers a broader range of cognitive processes. Among them would be the multimedia comprehension. Following this reasoning, by working on multimedia reading comprehension we are helping its textual improvement. This reasoning does not help change the forming methodology if a textual field is simply replaced with and multimedia one. This is why it is pertinent to add Mayer's theory here. As explained earlier, multimedia methodology can help a student's motivation towards knowledge, and it is a more complex cognitive understanding process than textual comprehension. However, it should be noted that by being more complex does not mean that it has to be beneficial per se, but, with a good design, it is a methodology that greatly helps their pedagogical effectiveness (Fletcher and Tobias, 2005, p. 120). Taking in consideration these two theories, we have the theoretical explanation of the hypothesis in question. When the teacher tries to get its pedagogical objectives, a multimedia methodology can be a very useful tool, better than a traditional one, which is very far away from the multimedia environment in which the students interact.

Along with these concepts, this factor was also studied in a timely assessment with sub-hypothesis 2 (H2): "We expect to observe significant differences in the number of question mistakes that the multimedia and textual student makes during the final evaluation test. Specifically, we expect to find fewer mistakes in the multimedia students”.

\section{MATERIALS AND METHODOLOGY}

The research was carried out for one year with two groups of 25 students each.

For textual support, Language and Literature $4^{\circ} \mathrm{ESO}$, the Editorial Oxford, Adarve-Trama series was used. Multimedia materials were also sourced on the web and exercises were created responding to the four areas proposed by the textbook to work on reading comprehension:

(4) Extraction of inferential information.

(5) Extraction of literal information.

(6) Lexicon.

(7) Spelling and grammar.

Thus, the work of six teaching units on reading comprehension in the textbook was chosen specifically. In addition, the visual exercises were removed, leaving only the purely textual that responded to the four areas previously mentioned.

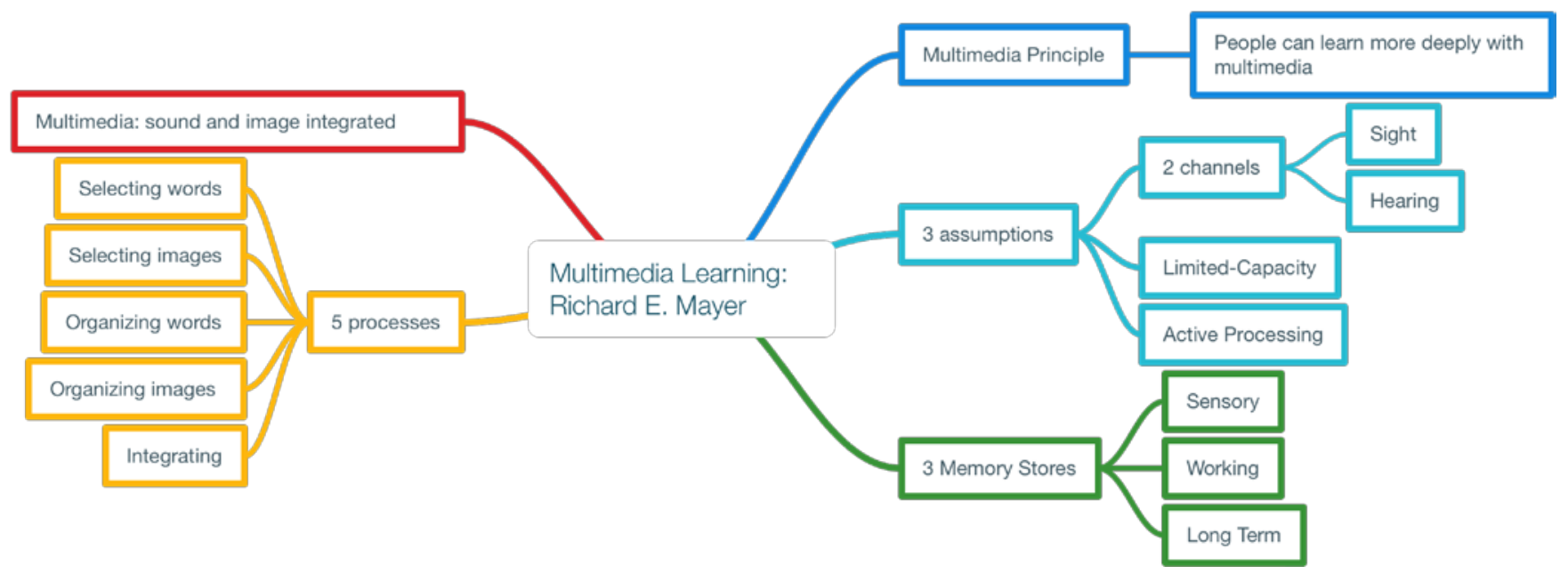

Figure 2. Multimedia Learning graphic summary 
Regarding the multimedia exercises, the classroom blog was used as support, because it offered many possibilities, it was simple, and the students were accustomed to working with it since it is often used.

The selection of the sample of participants was not carried out probabilistically, indeed, it was a non-probability convenience sampling, where participants have been deliberately chosen as research participants because they are more suitable than others to meet the objectives of analysis. It couldn't have been done differently since the researcher was required to collect data while performing his daily teaching in the context explained above.

Although it was controlled that the answer would not be affected by certain confounding variables (ensure a balanced level of reading), the fact that the chosen students have a defined profile (determined by the educational context of a high social and economic level private school) makes the generalization to other educational contexts (public schools or schools with another student profile) impossible.

\section{FIELDWORK}

Firstly we effected a reading evaluation of the two groups to discover if the level was even. To this end, the test PROLEC ${ }^{\text {iii }}$ was used, prior to family authorization and in collaboration with the Student Support Department.

Once it was found that the level was similar and that there were no participants who scored well below the normality, the field research started. Six exercises of each type were performed. In the exercises, we worked on the four areas previously mentioned.

Both the textual and multimedia exercises worked with different textual formats and multimedia materials.

The multimedia exercises that the students carried out were being uploaded to the classroom's blog, http://jugarconlaliteratura.blogspot.com/, with the tag "Comprensión lectora"; this way, having videos in the blog and the text of the questions that were being used, the students could refer to them as the same way as the students that were doing the exercises with their textbook at home.

The classroom was equipped with a digital cart, a portable computer per student, and internet. The teacher brought headphones from home so they could watch the videos (all hosted on the digital platform YouTube), as many times as they wanted. The two study groups carried out the exercises on paper and by hand.

The correction was made collectively in the classroom, and then again by the teacher. Both, the study group of students who did multimedia exercises, hereinafter "MULT"; as well as the study group carrying out textual exercises, hereinafter "TXT" could refer to their text or video as many times as needed.

Monitoring student's development was done individually and using the following table:

Table 2. Monitoring chart

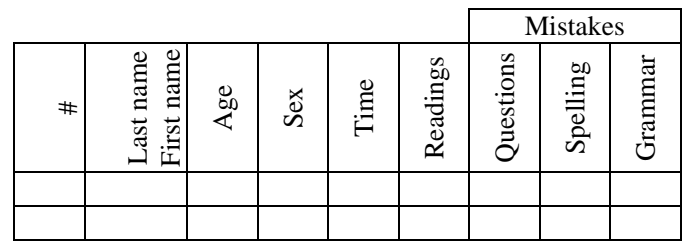

The student, as a rule, needed two sessions to perform the exercises and correct them, both multimedia and textual.

After completing all the exercises, at the end of the course, the teacher prepared an assessment test. It was intended to be performed in one session of forty minutes, and the evaluation criterion was the same as in the exercises. The only exception was that both the MULT and the TXT were only allowed to watch the video once.

\section{DATA ANALYSIS}

The performed statistical analyses have allowed putting the hypothesis of this study to the test.

To this end, we used the technique of analysis of variance (ANOVA) with repeated measures to study the evolution in reading comprehension depending on the methodology used (multimedia or textual) (H1). For H2 (the relationship between performance in reading comprehension and methodology) the technique of comparison of two independent samples was used, in its parametric side (t-Test) when it meets the assumption of normality in each group or its non-parametric side (MannWhitney $U$ test) when such normality does not occur.

Also, effect size measures, as Eta-squared $\left(\eta^{2}\right)$ (for ANOVA), Cohen's d (for t-Test) are provided, in order to provide information on the practical relevance of the relationships that have resulted as significant.

\section{RESULTS}

With the intention of responding to the hypotheses that we raised in the introduction, we will present the results in two sections. The first section reflects the analysis of data obtained during the exercises throughout the course (longitudinal analysis). The second presents the results in the final evaluation exercise.

\subsection{Results throughout the year}

We analyse, longitudinally, if there are differences in the measure of question mistakes by exercise (see summary values in Table 3). Specifically, we analyse whether one group has more question mistakes (wrong answers) than the other.

Table 3. Questions mistakes per exercise

\begin{tabular}{|c|c|c|c|c|}
\hline Exercise & & TXT & MULT & Total \\
\hline \multirow{3}{*}{1} & AVG & 23,76 & 11,8 & 17,78 \\
\hline & SD & 8,151 & 4,805 & 8,963 \\
\hline & $\mathrm{N}$ & 25 & 25 & 50 \\
\hline \multirow{3}{*}{2} & AVG & 25,88 & 9 & 17,44 \\
\hline & SD & 11,099 & 4,123 & 11,889 \\
\hline & $\mathrm{N}$ & 25 & 25 & 50 \\
\hline \multirow{3}{*}{3} & AVG & 13,65 & 14,92 & 14,285 \\
\hline & SD & 4,215 & 3,04 & 3,694 \\
\hline & $\mathrm{N}$ & 25 & 25 & 50 \\
\hline \multirow{3}{*}{4} & AVG & 13,65 & 6,15 & 9,9 \\
\hline & SD & 4,216 & 1,877 & 1,877 \\
\hline & $\mathrm{N}$ & 25 & 25 & 50 \\
\hline \multirow{3}{*}{5} & AVG & 15,12 & 17,777 & 16,449 \\
\hline & SD & 4,003 & 5,302 & 4,84 \\
\hline & $\mathrm{N}$ & 25 & 25 & 50 \\
\hline \multirow{3}{*}{6} & AVG & 23,949 & 7,16 & 15,554 \\
\hline & SD & 4,957 & 3,051 & 9,407 \\
\hline & $\mathrm{N}$ & 25 & 25 & 50 \\
\hline
\end{tabular}


If we analyse the average values (Table 3 , Figure 1), the mistakes vary throughout the six classroom exercises, differently in each group, with a significant interaction effect Evolution $\mathrm{x}$ Group (ANOVA analysis detailed hereafter). As can be seen graphically (Figure 1), the MULT group decreases its number of mistakes, while TXT, despite having the same number of mistakes in Exercise 3, then increases the number of mistakes again.

The ANOVA analysis of the evolution of these mistakes (with Greenhouse-Geisser correction) indicates that there is significant interaction, $F(3.3,158.4)=40.37, p<.001, \eta^{2}=.457$, between the evolution of question mistakes in the exercises and the groups being compared. This shows that there is a different pattern of evolution in the decrease of question mistakes in the six tests when comparing the groups (TXT vs. MULT). Specifically, the MULT students are the ones who demonstrate a more positive development.

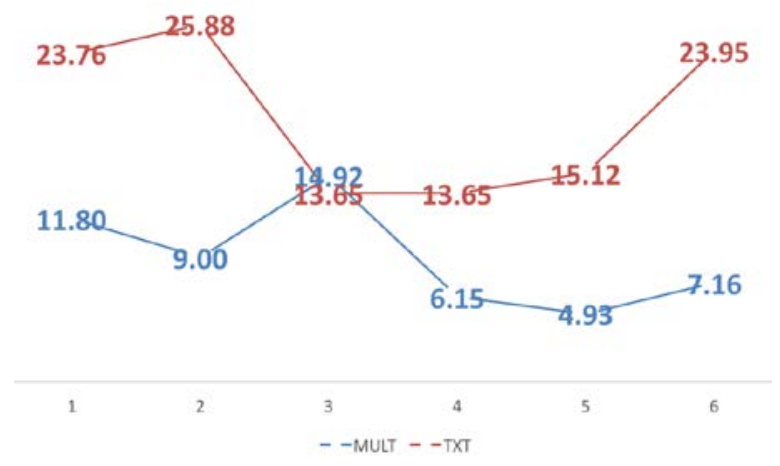

Figure 3. Evolution of the number of question mistakes

Finally, if we analyse the main effect of the group, the average number of question mistakes (assessments averaged 1-6) is significantly different between the groups, $F(1,48)=79.826$; $p$ $<.001$, the multimedia group being more accurate $(M=11.146$, $S D=2.130)$ than the textual group $(M=19.346 ; S D=4.064)$, with an effect size (effect of the activity on the recorded response) of $62 \%\left(\eta^{2}=.624\right)$. Therefore, MULT students make less mistakes than TXT students, the practical relevance of the differences being found high, given that the type of performed activity would explain $62 \%$ of the observed variability.

\subsection{Results obtained in the evaluation test}

In this section, we present the descriptive statistics of the measurement of question mistakes in the final evaluation test (Table 4).

Table 4. Questions mistakes in the evaluation test

\begin{tabular}{cccc}
\hline Group & AVG & SD & N \\
\hline TXT & 2,28 & 1,173 & 25 \\
\hline MULT & 1,88 & 1,13 & 25 \\
\hline
\end{tabular}

To determine whether there are differences between groups, we used the Mann-Whitney $U$ test (in absence of normality of the response variable in the groups), the degree of significance being $p=.259$. Therefore, despite an increased occurrence of errors in the TXT group being observed, there are no significant differences between the group means.

\section{DISCUSSION}

As in the Results section, the data will be discussed through two subsections.

\subsection{Discussion of the results obtained in the longitudinal measurements}

Referencing the data we have analysed regarding the question mistakes, let's remember that the MULT group has fewer mistakes than the TXT group $(p<.001)$. The first averaging $11.15(S D=2.13)$ and the second $19.35(S D=4.1)$

As for evolution, it has been stressed that MULT students reduce their mistakes in a greater proportion than the TXT (Figure 1). With this data, we developed our second principle: A multimedia methodology to work on reading comprehension, properly designed, helps students to focus, reducing the number of response mistakes they make in the exercises and improving their evolution throughout the teaching process.

We will discuss these results through the "Multimedia Principle” by R. Mayer, which confirms that through multimedia materials, humans learn more than with traditional materials ${ }^{\text {iv }}$. Evidently, we are not discussing learning in itself here, but about the amount of information that a student can retain thus saving readings and making less answering mistakes. We are in a mnemonic, greatly researched by Mayer. In 2001 (Mayer, 2001), for example, demonstrated that using static diagrams and text showed a retention average of 0.86 and 1.36 of transference in students. This result becomes more pronounced when animations are being studied, since they already include image and sound (Mayer and Anderson, 1991; Moreno and Mayer, 2002). This data is consistent with our results, to greater retention, less need to resort to the source to find information in order to solve the exercises. Before we continue, we must remember that there are researchers that are very critical of this principle. Clark and Feldon (Clark and Feldon, 2005, 2014) state that there is not enough well-designed research to assert that multimedia learning can achieve something that cannot be done through non-multimedia. They say that the experiments that are proving it (Mayer, 2001) are poorly designed. In fact, they challenge any researcher to refute them.

In short, we see that the MULT students, contrary to what researchers Clark and Feldon think, need less readings to perform their activities, and besides, they make less mistakes. To this, we must add that their evolution is significantly better. They retain more information and their learning is more accurate by the application of the Multimedia Principle, or because the multimedia material motivates them more, a feature also allocated by Mayer to this type of educational material, and makes them focus more on the exercises.

The latter is an assertion that must be done with caution, even within the Multimedia Learning theory there is a principle called "Principle of divided attention" (Ayres and Sweller, 2005). This articulates that you have to be cautious with multimedia design because it can produce an understanding that is not integrated into the Mayer model, having the opposite effect and dividing. This causes an increase in the cognitive load with the consequent danger of overload. Fundamentally, this process occurs when different built-in formats are necessary to understand the material that is presented at the same time, producing a negative effect on the student that rejects the material. This principle should be applied when researchers create the materials. In our case, although we created the questions to make the exercises as similar as possible to the textual, the multimedia was not, as it 
was created by professionals (available in internet) to try and avoid this problem.

\subsection{Discussion on the results of the final evaluation test}

Now we proceed to discussing the results obtained in the evaluation test ${ }^{\mathrm{vi}}$. We have already noted that the comparison of the averages of the final exam results, regarding the question mistakes, did not indicate the existence of a significant difference between the mistakes of one or the other group (Table $4, p=.259$ ). Although the MULT have less errors, the difference is not significant. This result is inconsistent with the Multimedia Principle outlined before; let's develop this idea.

Learning with video has some obstacles when transferring information. Since the videos are very rich in information, the attention of viewers can go to the accessory and disregard the important information (Goldman-Segall, 1998; Miller 2011; Roschelle, 2000); we have also explained that even this format, without a proper design, can lead to cognitive overload that makes it hard to capture the really relevant elements. In addition, viewers can incorporate deep convictions to small video fragments, with a greater intensity than to text fragments (Ambaday \& Rosenthal, 1993; Miller \& Zhou, 2007). Some of these problems may have contributed to no significant difference between the two groups, or just the opposite, they have shown fewer errors because the format made them more focused on the task. Since we don't have data of a test with the opposite format, we can not assert it, but it should be noted that the multimedia format has proven effective even in the teacher training (Derry, Sherin, \& Sherin, 2014) field in which several studies have been conducted, demonstrating the efficacy (Derry, Hmlo-Silver, Nagarajan, Chernobilsky and Beitzel, 2006; Santagata, Gallimore, and Stigler, 2005; Sherin, Jacobs and Philipp, 2011)

\section{CONCLUSIONS}

The conclusions we have reached after the analysis of our data and the corresponding discussions are:

A Multimedia methodology to develop the textual comprehension, properly designed, helps the educational process to be more effective because students make fewer mistakes when answering questions.

Furthermore, we have seen that at the time of the evaluation, the introduction of a multimedia methodology compared to a textual presentation does not improve (at least in absolute terms), the student's ability of success when responding.

As mentioned above, the main limitation of this study is that it is not possible to generalize the results of other educational contexts, due to the use of a non-probability sampling; therefore, we must be cautious when applying these conclusions, only to the context of this research and its participants.

As indicated in the introduction of the article, the first part of a PLE should combine textual reading with multimedia, given that they respond to common mechanisms. We have shown that they enrich the evolutionary process by making learning more accurate, although not so much in a timely assessment where we couldn't see any differences in the ability of success when answering questions. This data, far from being trivial, agrees faithfully with the philosophy of PLE's theory that seeks to improve the learning process and is not focused on the evaluation, but on the evolution.
Finally, our investigation continues and we are expanding it to university contexts, with a higher study population and probability sampling.

\section{REFERENCES}

Adell, J., \& Castañeda, L. (2010). Los Entornos Personales de Aprendizaje (PLEs): una nueva manera de entender el aprendizaje. In R. Roig \& R. Fiorucci (Eds.), Claves para la investigación en innovación y calidad educativas. La integración de las tecnologías de la información y la Comunicación y la Interculturalidad en las aulas. Stumenti di ricerca per l'innovaziones e la qualità in ámbito educativo. La Tecnologie dell'informazione e della comunicaziones e l'interculturalità nella scuola. Alcoy/Roma: Marfil/ Universita degli studi TRE.

Ambady, N., \& Rosenthal, R. (1993). Half a minute: Predicting teacher evaluations from thin slices of nonverbal behavior and physical attractiveness. Journal of Personality and Social Psychology, 64, 431-441. doi:10.1037/00223514.64.3.431

Attwell, G. (2007). The Personal Learning Environments - the future of eLearning? eLearning Papers, 2(1).

Ayres, P., \& Sweller, J. (2005). The Split-Attention Principle in Multimedia Learning. In R. E. Mayer (Ed.), The Cambridge handbook of multimedia learning (pp. 135-146). New York: Cambridge University Press. doi:10.1017/CBO9780511816819.009

Barthes, R. (1964). Rhétorique de l'image. Communication, 4(1), 40-51. doi: 10.3406/comm.1964.1027

Castañeda, L., \& Adell, J. (2011). El desarrollo profesional de los docentes en entornos personales de aprendizaje (PLE). In R. Roig \& C. Lavene (Eds.), La práctica educativa en la sociedad de la información: innovación a través de la investigación. Alcoy: Marfil.

Castañeda, L., \& Adell, J. (Eds.) (2013). Entornos Personales de Aprendizaje: claves para el ecosistema educativo en red. Alicante: Marfil.

Chaves, B. E. (2014). Autogestión del aprendizaje en la investigación educativa sobre Entornos Personales de Aprendizaje (PLE): una revisión de literatura. Edmetic, Revista de Educación Mediática y TIC, 3(2), 114-134.

Clark, R. E., \& Feldon, D. (2005). Five Common but QuChavez-estionable Principles of Multimedia Learning. In R. E. Mayer (Ed.), The Cambridge handbook of multimedia learning (pp. 97-115). New York: Cambridge University Press. doi:10.1017/CBO9780511816819.007

Clark, R. E., \& Feldon, D. (2014). Ten Common but Questionable Principles of Multimedia Learning. In R. E. Mayer (Ed.), The Cambridge handbook of multimedia learning (2nd Ed.) (pp. 151-173). New York: Cambridge University Press. doi:10.1017/CBO9781139547369.009

Derry, S. J., Hmlo-Silver, C. E., Nagarajan, A., Chernobilsky, E., \& Beitzel, B. (2006). Cognitive transfer revisited: Can we exploit new media to solve old problems on a large scale? Journal of Educational Computing Research, 35, 145-162. doi:10.2190/0576-R724-T149-5432

Derry, S. J., Sherin, M. G., \& Sherin, B. L. (2014). Multimedia Learning with Video. In R. E. Mayer (Ed.), The Cambridge handbook of multimedia learning (2nd Ed.) (pp. 785-812). New York: Cambridge University Press. doi:10.1017/CBO9781139547369.038

Fletcher, J. D., \& Tobias, S. (2005). The Multimedia Principle. In R. E. Mayer (Ed.), The Cambridge handbook of multimedia learning (pp. 97-115). New York: Cambridge University Press. doi:10.1017/CBO9780511816819.008

Gernsbacher, A. M. (1985). Surface information loss in comprehension. Cognitive Psychology, 17, 324-363. doi:10.1037/0278-7393.16.3.430

Gernsbacher, A. M., Varner, K. R., \& Faust, M. (1990). Investigating differences in general comprehension skill. Journal of Experimental Psychology: Learning, Memory, and Cognition, 16, 430-445. doi:10.1037/0278-7393.16.3.430

Gernsbacher, A. M. (1995). The Structure-Building Framework: What it is, What it might also be, and Why. In B. K. Britton \& A. C. Graessens (Ed.), Models of text understanding. Hilldale, N. J.: Erlbaum.

Gernsbacher, A. M. (1997). Two decades of Structure Building. In A. Graesser (Ed.), Discourse Processes (Vol. 23). Greenwich, Connecticut: Ablex Publishing Corporation. doi:10.1080/01638539709544994

Goldman-Segall, R. (1998). Points of viewing children's thinking: A digital ethnographer's journey. Mahwah, NJ: Lawrence Erlbaum.

Lobato, R., \& Lahera, A. (2011). Lengua castellana y literatura. Madrid: Oxford University Press.

Mayer, R. E. (2001). Multimedia Learning. New York: Cambridge University Press. doi:10.1017/CBO9781139164603

Mayer, R. E. (2005). Cognitive theory of Multimedia Learning. In R. E. Mayer (Ed.), The Cambridge handbook of multimedia learning (pp. 31-48). New York: Cambridge University Press. doi:10.1017/CBO9780511816819.004

Mayer, R. E. (2005) (Ed.). The Cambridge handbook of multimedia learning. New York: Cambridge University Press. doi.org/10.1017/cbo9780511816819 
Mayer, R. E. (2014) (Ed.). The Cambridge handbook of multimedia learning (2nd Ed.). New York: Cambridge University Press. doi:10.1017/CBO9781139547369

Mayer, R. E. (2008). Multimedia Literacy. In J. Coiro, M. Knobel, C. Lankshear, \& D. J. Leu (Eds.), Handbook of research on new literacies (pp. 359-376). New York/London: Lawrence Erlbaum Associates.

Mayer, R. E. (2011). Applying the Science of Learning to Multimedia Instruction. In J. P. Mestre, \& B. H. Ross (Eds.), The psychology of learning and motivation, cognition in education (Vol. 55, pp. 77-103). Elseiver INC. doi:10.1016/b978-0-12-387691-1.00003-x

Mayer, R. E. (2014). (Ed.). The Cambridge handbook of multimedia learning (2nd ed.). New York: Cambridge University Press.

Mayer, R. E., \& Anderson, R. B. (1991). Animations need narrations: An experimental text of a dual-coding hypothesis. Journal of Educational Psychology, 83(4), 484-490. doi:10.1037/0022-0663.83.4.484

Mayer, R. E., \& Anderson, R. B. (1992). The instructive animation: Helping students build connections between words and pictures in multimedia learning. Journal of Educational Psychology, 84, 444-452. doi:10.1037/00220663.84.4.444

Mayer, R. E., \& Chandler, P. (2002). When learning is just a click away: Does simple user interaction foster a deeper understanding of multimedia messages? Journal of Educational Psychology, 93(2), 390-397. doi:10.1037/00220663.93.2.390

Mayer, R. E., \& Massa, L. J. (2003). Three facets of visual and verbal learners: Cognitive ability, cognitive style, and learning preference. Journal of Educational Psychology, 95(4), 833-846. doi:10.1037/0022-0663.95.4.833

Miller, K. F. (2011). Situation awareness in teaching: What educators can learn from video-base research in other fields. In M. G. Sherin, V. R. Jacobs, \& R. A. Philipp (Eds.), Mathematics teacher noticing: Seeing through teachers' eyes (pp. 51-65). New York: Routledge.

Miller, K. F., \& Zhou, X. (2007). Learning from classroom video: What makes it compelling and what makes it hard. In R. Goldman, R. Pea, B. Barron, \& S Derry (Eds.), Mathematics teacher noticing: Seeing through teachers' eyes (pp. 51-65). New York: Routledge.

Moreno, R., \& Mayer, R. E. (2002). Verbal redundancy in multimedia learning: When reading helps listening. Journal of Educational Psychology, 94(1), 358368. doi:10.1037/0022-0663.94.1.156

Naím, M. (2007). The Youtube Effect. Foreign Policy, 158, 104-103.

Orús, C., Barlés, M. J., Belanche, D., Casaló, L., Fraj, E., \& Gurrea, R. (2016). The effects of learnier-generated videos for YouTube on learning outcomes and satisfaction. Computers \& Education, 95, 254-269. doi:10.1016/j.compedu.2016.01.007

Perfetti, C. A., \& Goldman, S. R. (1976). Discourse memory and reading comprehension skill. Journal of Verbal Learning and Verbal Behavior, 15, 33-42. doi:10.1016/S0022-5371(76)90004-9

Perfetti, C. A., \& Lesgold, A. M. (1977). Disclosure comprehension and sources of individual differences. In M. A. Just \& P. A. Carpenter (Eds.), Cognitive processes in comprehension (pp. 141-183). Hilldale, NJ: Erlbaum.

Roschelle, J. (2000). Choosing and using video equipment for data collection. In A. E. Kelly \& R. A. Lesch (Eds.), Research design in mathematics and science education (pp. 709-731). Mahwah, NJ: Lawrence Erlbaum.

Santagata, R., Gallimore, R., \& Stigler, J. W. (2005). The use of videos for teacher education and professional development: Past experiences and future directions. In C. Vrasidas \& G.V. Glass (Eds.), Current perspectives on applied information technologies: Preparing teachers to teach with technology (pp. 151167). Greenwich, CT: Information Age.

Sherin, M. G., Jacobs, V. R., \& Philipp, R. A. (Eds.) (2011). Mathematics teacher noticing: Seeing through teachers 'eyes. New York: Routledge.

Sweller, J. (1988). Cognitive load during problem solving: Effects on learning. Cognitive Science, 12, 257-285. doi:10.1207/s15516709cog1202_4

Sweller, J., Chandler, P. Tierney, P., \& Cooper, M. (1990). Cognitive load and selective attention as factors in the structuring of technical material. Journal of Experimental Psychology: General, 119, 176-192. doi:10.1037/00963445.119.2.176

van Harmelen, M. (2008). Design trajectories: four experiments in PLE implementation. Interactive Learning Evioronments, 16(1), 35-46. doi:10.1080/10494820701772686

\section{NOTES}

${ }^{\mathrm{i}}$ It is necessary to remember that we are only describing the investigative theory. We are not analysing all the possible learning problems or different theories of human comprehension. ii It should be noted again that this is Doctor Gernsbacher's theory. We wish to point out, for example, that in the case of a dyslexic person this statement is not correct.

iii Assessment battery of reading processes (Cuetos, Rodríguez \& Ruano, 2000)

iv In 1964, Roland Barthes was already talking about a phenomenon named "anchoring", although he did so as a guide to help the recipient obtain the most relevant information of a textual message relying on the image. He explained it through marketing images because they are clearly intentional (Barthes, 1964).

${ }^{v}$ The Split-Attention Principle (Mayer, 2005)

${ }^{v i}$ It is expected to see significant differences in the number of question mistakes that an multimedia student makes and a textual student during the final evaluation test. Specifically, it is expected to find fewer mistakes in the multimedia students.

How to cite this article:

García, J.D.; Rigo, E. \& Jiménez, R. (2017 Multimedia and Textual

Reading Comprehension: Multimedia as Personal Learning

Environment's Enriching Format. Journal of New Approaches in

Educational Research, 6(1), 3-10. doi: 10.7821/naer.2017.1.180 